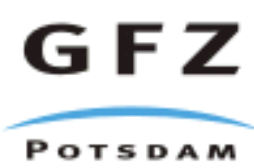

Originally published as:

Klemann, V., Wolf, D. (1998): Modelling of stresses in the Fennoscandian lithosphere induced by Pleistocene glaciations. - Tectonophysics, 294, 3-4, 291-303,

DOI: 10.1016/S0040-1951(98)00107-3. 


\title{
Modelling of stresses in the Fennoscandian lithosphere induced by Pleistocene glaciations
}

\author{
Volker Klemann ${ }^{1}$ and Detlef Wolf ${ }^{2}$
}

Manuscript submitted to

Tectonophysics

Manuscript version of 5 January 1997

Revised version of 31 December 1997

\footnotetext{
${ }^{1}$ Institute of Planetology, University of Münster,

Wilhelm-Klemm-Str. 10, D-48149 Münster, Germany

${ }^{2}$ GeoForschungsZentrum Potsdam,

Telegrafenberg A17, D-14473 Potsdam, Germany
} 


\begin{abstract}
The seismicity observed in Fennoscandia is usually explained by $t \epsilon c$ tonic stresses. The question of the contribution of stresses induced by glacial-isostatic adjustment to the seismicity has not finally been settled yet. In order to quantify the isostatic stress field generated by the Fennoscandian glacial load, we consider layered Maxwell-viscoelastic half-spaces loaded by axisymmetric discs. In particular, we calculate the maximum shear-stress distribution induced by the load model and the associated stress regimes in the lithosphere. Emphasis is placed on a discussion of the sensitivity of the calculated isostatic stresses to variations in load cross-section, lithosphere thickness and asthenosphere viscosity. We also examine the effects produced by the viscous relaxation of the lithosphere, whose viscosity is parameterized according to the stratification expected for temperature-activated diffusion creep.

Our results show that the isostatic shear stresses typically reach $\sim 2 \mathrm{MPa}$ near the surface at the present time but that their distribution may be modified strongly by the details of the earth and load models investigated. The viscous relaxation of the lithosphere becomes particularly important, if more than one glaciation is considered. Since the last ice age in Fennoscandia consisted of several glaciations, the model of a perfectly elastic lithosphere conventionally employed in models of glacialisostatic adjustment therefore may not be justified when calculating the isostatic stresses.
\end{abstract}




\section{Introduction}

The existence of late- and post-glacial faults in northern Sweden has usually been related to the glacial-isostatic rebound accompanying and following the retreat of the last ice sheet in Fennoscandia (e.g. Lagerbäck, 1979; Muir Wood, 1989; Arvidsson, 1996). A mechanical explanation of this relation was given by Johnston (1987, 1989), who showed how the strain energy stored in the lithosphere during the loading by continental ice sheets can be released after their disappearance. This explanation was confirmed in model calculations for the Canadian ice sheet by $\mathrm{Wu}$ and Hasegawa (1996a,b), who demonstrated that the predicted time of fault instability coincides with the times of the late- and post-glacial faulting events in northern Canada. A similar result has recently been obtained for Fennoscandia by Johnston et al. (1998).

In contrast to this is the present stress field in Fennoscandia, which is dominated by the tectonic stresses propably in the range of $10-50 \mathrm{MPa}$, which are associated with the Mid-Atlantic rifting and the European-African plate collision (e.g. Stein et al., 1989; Grünthal and Stromeyer, 1992; Müller et al.,1992). As a consequence, most earthquakes in Fennoscandia with magnitudes up to 6 are related to tectonic structures along the Norwegian continental shelf and explained by ridge push (Bungum, 1989). The earthquakes in the interior of the Fennoscandian Shield rarely exceed magnitude 4 and can be divided into two groups located in southwestern Sweden and northern Sweden, respectively (Slunga, 1989; Wahlström, 1989). The spatial correlation of the group in northern Sweden with the centre of the last ice sheet suggests a connection with the loading effects of the Fenoscandian glaciation.

However, the question of a causal relationship between the recent seismicity and the continuing glacial-isostatic adjustment in Fennoscandia has not finally been settled yet (Wahlström, 1993). Thus, from an analysis of the present stress directions, Gregersen (1992) did not see any evidence for a connection of the present seismicity with post-glacial adjustment. On the other hand, Müller et al. (1992) pointed out that, compared to the other parts of Europe, a considerable scatter of the stress 
orientations exists in northern Europe. Similarly, Skordas and Kulhánek (1992) observed an increase of the seismic $b$-value (ratio between the numbers of low- and high-magnitude earthquakes) towards the centre of the final Weichselian glaciation in Fennoscandia, which suggested to them a contribution to seismicity other than tectonic stresses in this area.

A corresponding discussion exists about the origin of the enhanced seismicity observed in parts of eastern Canada. In view of the larger thickness of the Canadian ice sheet, the contribution of the glacial-isostatic stresses was more important than in Fennoscandia at the end of the last glaciation. According to model calculations, their superposition with the tectonic stresses was able to change the orientation of the dominant horizontal stress component significantly at that time. At present, the isostatic stresses in eastern Canada are much smaller and largely masked by the tectonic stress field (Wu, 1996, 1997).

To assess the possible contribution of the glacial-isostatic adjustment to seismicity, it is necessary to consider the influence of a time-dependent surface load on the stress field in the lithosphere. In the first approximation, its response can be described as the flexure of a perfectly elastic plate superimposed on a fluid substratum (e.g. Comer, 1983; Wolf, 1985a). Then, the forces balancing the load pressure are the elastic bending forces of the plate and the gravitational buoyancy forces of the substratum. If the viscoelasticity of the substratum is taken into account, the response of the plate is modified and retarded, and the time needed to reach equilibrium depends on the viscosity of the layers and the details of their stratification (e.g. Wolf, 1985b).

For a standard earth model with a perfectly elastic lithosphere of $100 \mathrm{~km}$ in thickness overlying a viscoelastic mantle of $10^{21} \mathrm{~Pa} \mathrm{~s}$ in viscosity (earth model $\mathrm{E}$, Table 1), the response to glacial loading can be characterized as follows. Assuming a slow build-up of the ice sheet during $\sim 10^{5}$ a - much longer than the relaxation times for the earth model (Fig. 1) - the lithosphere is in a state of maximum stress at the glacial maximum. However, at the end of the much faster deglaciation during 
$\sim 10^{4}$ a, the lithosphere has not regained a stress-free state yet. This is because the relaxation times of the dominant relaxation mode M0 of the viscoelastic mantle are $\sim 5 \times 10^{3}$ a for the wave numbers of $10-20$ relevant to the Canadian and Fennoscandian glaciations (Fig. 1).

In more realistic models, the lithosphere is represented as a viscoelastic layer. Its replacement by a perfectly elastic layer of suitable thickness requires that the loading time is short compared to the relaxation times associated with the viscoelastic response of the lithosphere. This condition is approximately satisfied, if the response to a single glaciation with a duration of $\sim 10^{5}$ a is considered. However, the northern hemisphere is known to have been subjected to a sequence of glaciations during the Pleistocene ice age (Shackleton et al., 1984). Typically, it is assumed that ten glaciations with a duration of $\sim 10^{5}$ a each represent this ice age such that its characteristic time is $\sim 10^{6}$ a. This is no longer short compared to the relaxation times associated with the viscoelastic lithosphere, and its response to loading may therefore more appropriately be modelled using a series of viscoelastic layers.

In the present study, we investigate the perturbation of the tectonic stress field in the lithosphere induced by the Pleistocene glaciations in Fennoscandia. Since our objective is not the accurate prediction of the isostatic stress field but the identification of the parameters that influence it, we may use simplified earth and load models. Beyond the scope of our study is also an assessment of the impact of our results on the question of the origin of the seismicity in Fennoscandia, which would require the superposition of the tectonic and isostatic stress fields and the analysis of the total stress field in terms of a faulting criterion, such as Coulomb's criterion (Johnston,1989; Wu and Hasegawa, 1996a,b; Wu, 1997) or a criterion based on strain rates (James and Bent, 1994).

The calculations to be presented are based on the theory developed for a Maxwellviscoelastic half-space subjected to an axisymmetric surface load (Sect. 2). We begin with a brief description of the spatial distribution and temporal evolution of the isostatic-stress in a perfectly elastic lithosphere (Sect. 3.1). Following this, we 
study the influence of the load cross-section on the response (Sect. 3.2), look the effects produced by a change in lithosphere thickness (Sect. 3.3), and examine the modifications due to the presence of a low-viscosity asthenosphere (Sect. 3.4). We continue by investigating the effects on the isostatic stress field (Sect. 4). The study concludes with a brief summary and discussion of the results obtained (Sect. 5).

\section{Theoretical model}

We consider the response of the Earth to a perturbing load pressure at its surface and model the Earth as an incompressible layered material half-space with constant properties in each layer. Assuming that the material is initially in a state of hydrostatic stress and subsequently undergoes quasi-static perturbations, the incremental momentum equation takes the form

$\partial_{j} \sigma_{i j}+\rho g\left(\partial_{3} u_{3}\right) \delta_{i 3}=0$,

where $\sigma_{i j}$ is the material incremental stress, $\rho$ the mass density, $g$ the initial gravity, $u_{i}$ the displacement and $\delta_{i j}$ the Kronecker delta (for details see Wolf, 1991). The subscript 3 denotes the downward direction and $\partial_{i}$ partial differentiation with respect to the $i$ th coordinate direction. Note that dilatational stresses are assumed to be positive in this study. The incremental continuity equation for an incompressible material reduces to

$\partial_{i} u_{i}=0$.

We use the Maxwell-viscoelastic relation between stress and strain as the incremental constitutive equation. It may be written as

$\sigma_{i j}=-p \delta_{i j}+\int_{0}^{t} \mu\left(t-t^{\prime}\right) \partial_{t^{\prime}}\left[\partial_{i} u_{j}\left(t^{\prime}\right)+\partial_{j} u_{i}\left(t^{\prime}\right)\right] d t^{\prime}$,

where $p$ is the material incremental pressure, $t$ and $t^{\prime}$ are the current time and the excitation time, respectively, $\partial_{t^{\prime}}$ denotes differentiation with respect to $t^{\prime}$, and

$\mu(t)=\mu_{e} e^{-\frac{t}{\tau}}$ 
is the shear-relaxation function parameterized by the elastic shear modulus, $\mu_{e}$, and the Maxwell time, $\tau$ (e.g. Wolf, 1991). The viscosity, $\eta$ is related to $\mu_{e}$ and $\tau$ by $\eta$ $=\mu_{\epsilon} \tau$.

The incremental field equations, (1)-(4), are solved using Laplace transformation with respect to $t$. In particular, this transformation converts the convolution integral (3) into a relation formally equivalent to Hooke's law with the effective shear modulus given by $\mu(s)=\mu_{e} s /\left(s+\tau^{-1}\right)$, where $s$ is the inverse Laplace time. In the following, we will assume axisymmetric loads. Introducing cylindrical coordinates, $(r, \varphi, z)$, with $r$ the radial distance, $\varphi$ the azimuth and $z$ the depth, the dependence on $\varphi$ may be eliminated in this case. Hankel transformation with respect to $r$ then yields a first-order ordinary differential system in the $(k, z, s)$ domain with $k$ the Hankel wave number, which is solved analytically for appropriate boundary, interface and regularity conditions. The solution in the $(r, z, t)$ domain is obtained upon inverse Hankel and Laplace transformations (Appendix; for details see Wolf, 1985b; Brener and Wolf, 1995).

As a measure of the stress field in the $(r, z, t)$ domain, we employ the maximum shear stress. It can be expressed in terms of the maximum and minimum principal stresses, $\sigma_{1}$ and $\sigma_{3}$, respectively, as

$\sigma_{s s}=\frac{1}{2}\left(\sigma_{1}-\sigma_{3}\right)$

The stress field can also be characterized by distinguishing between the extension regime, the strike-slip regime and the thrust regime, depending on whether the minimum, intermediate or maximum principal stress, respectively, is closest to the vertical direction. We note again that the stress field calculated in this study is always the isostatic stress field. It therefore represents a perturbation of the tectonic stress field, which is mainly in a state of thrust in Fennoscandia. 


\section{Computational results for elastic lithosphere}

\subsection{General features}

We begin with an overview of the basic features of the isostatic stress field in the lithosphere in response to the Fennoscandian glacial load. We use earth model E (Table 1) with a lithosphere thickness of $h_{1}=100 \mathrm{~km}$. The glacial load is represented by a circular disc with elliptic cross-section, a radius of $r_{L}=900 \mathrm{~km}$ and an axial thickness of $h_{L}=2800 \mathrm{~m}$ (load model E, Table 2). The thickness is chosen to produce a maximum pressure of $25 \mathrm{MPa}$ at the load axis. The loading history comprises a linear increase of the load thickness over a period of $90 \mathrm{ka}$ and a linear decrease over a period of $10 \mathrm{ka}$. This is a simplified representation of the final Weichselian glaciation in Fennoscandia, which ended $\sim 8$ ka BP (before present) (e.g. Lundqvist, 1986). The calculations apply to the following epochs: the last glacial maximum (LGM) at $18 \mathrm{ka} \mathrm{BP}$, the end of deglaciation (EOD) at $8 \mathrm{ka} \mathrm{BP}$ and the present time (PT).

Figure 2 shows the maximum shear stress and the stress regimes in the lithosphere for the three epochs. At the LGM, the stress field is similar to that in a loaded elastic plate overlying a fluid half-space (e.g. Stein et al.. 1979) and therefore characterized by two maxima inside and two maxima outside the load margin. Their magnitudes are nearly equal and of the same order as the load pressure. The two maxima near the surface of the lithosphere are associated with thrust below the load and extension in its periphery. Near the base of the lithosphere, the signs are inverted. Here, the stress maximum below the load corresponds to extension and the stress maximum peripheral to the load to thrust.

During the relaxation, the position of the maxima remains nearly fixed, whereas their magnitudes decrease. When the load pressure has vanished at the EOD, the values of the maximum shear stress are about half of those at the LGM. The shear stresses continue to relax after the EOD, but may still reach $\sim 2 \mathrm{MPa}$ at the PT. Closer inspection of Fig. 2 shows that the surface of vanishing shear stress located 
at a depth of $50 \mathrm{~km}$ below the load at the LGM shifts downward during the relaxation. Simultaneously, the inner maxima, which extend towards the load axis at the LGM, become more localized, and the oscillatory pattern of the stress field with a wavelength of $\sim 1000 \mathrm{~km}$ becomes visible more clearly. These features are a result of the viscoelastic redistribution of mantle material during the relaxation leading to shear stresses in the upper mantle that are coupled with the stress field in the lithosphere.

In the following subsections, we will discuss the modifications of these characteristics due to variations of load cross-section, changes of lithosphere thickness and effects due to the presence of an asthenosphere.

\subsection{Influence of load cross-section}

Next, the influence of the load cross-section on the isostatic stress field is studied. For this purpose, we consider loads with axial thicknesses of $h_{L}=2800 \mathrm{~m}$, radii of $r_{L}=900 \mathrm{~km}$ and rectangular (load model R), elliptic (load model E) or parabolic (load model P) cross-sections (Table 2), whose volumes are related as 3 to 2 to 1.5, respectively. The differences between the cross-sections lead to different distributions of the load pressure. Thus, for the rectangular cross-section, the pressure changes discontinuously from $25 \mathrm{MPa}$ to zero at the margin. The pressure for the elliptic cross-section decreases continuously towards zero at the margin, but has an infinite gradient at this point. In contrast to this is the parabolic cross-section, which has a finite pressure gradient also at the margin. The following calculations apply to earth model E (Table 1) with a lithosphere thickness of $h_{1}=100 \mathrm{~km}$ and to the LGM.

Figure 3 shows the effects produced by changes of the load cross-section on the maximum shear stress and the stress regimes. For load model R, the stress maxima are located close to the load margin and have magnitudes similar to the load pressure. For load models $\mathrm{E}$ and $\mathrm{P}$, the inner maxima are broader and, in the latter case, extend to the load axis. The lateral extension of the outer maxima is nearly unaffected by the changes in cross-section. However, for load models $\mathrm{E}$ and $\mathrm{P}$, they are located 
closer to the load margin and their magnitudes are reduced.

A unique characteristic associated with load model $\mathrm{R}$ is a region of high shear stress located below the load margin at intermediate depths in the lithosphere. For a steep load margin, the maximum shear stress exhibits this feature also in an elastic half-space (Sneddon, 1951, p. 402ff). As can be shown, the stress component $\sigma_{r z}$ reaches a magnitude comparable to those of the other components in this region, which causes the principal stress directions to differ markedly from the horizontal and vertical directions.

\subsection{Influence of lithosphere thickness}

To assess the influence of the elastic lithosphere on the isostatic stress field, we choose lithosphere thicknesses of $h_{1}=50 \mathrm{~km}, 100 \mathrm{~km}$ and $150 \mathrm{~km}$ (earth model E, Table 1). This is the range of thicknesses suggested for the Fennoscandian lithosphere by most interpretations of glacial-isostatic adjustment (for a review see Wolf, 1993). The following calculations apply to load model E (Table 2) and the LGM.

Figure 4 shows that changes in lithosphere thickness do not affect the general pattern of the stress field. However, if the lithosphere thickness increases, the magnitudes of the inner maxima also increase, whereas those of the outer maxima decrease. These modifications are accompanied by a broadening of the maxima and their shifting away from the load margin, which, for a lithosphere thickness of $150 \mathrm{~km}$, leads to a location of the inner maxima on the load axis (Fig. 4, bottom). This behaviour is related to the extension of the bending of the thick lithosphere toward the load axis. For a smaller lithosphere thickness of $100 \mathrm{~km}$, similar axial stress maxima have been found for load model P (Fig. 3, centre). In this case, the axial maxima are related to the larger pressure gradient near the load axis for the parabolic cross-section as compared to the elliptic cross-section (Table 2).

The oscillatory pattern of the stress field mentioned above is displayed most clearly by the stress regimes and shows that the wavelength of the oscillation increases with increasing lithosphere thickness. As a consequence, the stress regimes may change 
repeatedly between extension and thrust in the periphery of the load provided that the lithosphere is sufficiently thin.

\subsection{Influence of asthenosphere viscosity}

Most studies of glacial-isostatic adjustment in Fennoscandia have suggested the presence of a low-viscosity asthenosphere below the lithosphere (e.g. Wolf, 1987; Fjeldskaar, 1994; Mitrovica, 1996). To study the modifications of the isostatic stress field due to this feature, we consider earth model A, whose asthenosphere has a thickness of $h_{2}=100 \mathrm{~km}$ and a viscosity of $\eta_{2}=1.0 \times 10^{19} \mathrm{~Pa} \mathrm{~s}$ (Table 1 ). The following calculations apply to load model E.

Figure 5 shows the maximum shear stress and the stress regimes for the three epochs considered. A comparison with Fig. 2 reveals the similarity of the stress fields for earth models E and A at the LGM. This demonstrates that both earth models are nearly in equilibrium before the beginning of deglaciation. However, on account of the reduced viscosity below the lithosphere in earth model A, the relaxation proceeds faster than for earth model E, and the similarity of the stress fields disappears. At the PT, the stress values for earth model A barely reach $\sim 1$ MPa.

Most conspicuous after the LGM is the pronounced asymmetry of the relaxation between the upper and lower layers of the lithosphere in earth model A, which is indicated only slightly for earth model E over this period. Obviously, the short relaxation times associated with the low-viscosity asthenosphere preferentially affect the depth range near the base of the lithosphere, where the stress relaxation is much more pronounced than near its top. At intermediate depths in the lithosphere, the stress values at the EOD may even be higher than at the LGM. Concomitant with these complications for earth model $\mathrm{A}$ is the modification of the stress regimes, where the regular change between extension and thrust evident at the LGM breaks down thereafter. 


\section{Computational results for viscoelastic lithosphere}

\subsection{Parameterization of viscosity}

A simple non-elastic model of the lithosphere comprises a brittle upper layer, an elastic middle layer and a ductile lower layer (e.g. Kusznir, 1991). To obtain a viscoelastic model, we disregard the brittle behaviour of the upper layer and include it in the elastic middle layer to form an elastic upper lithosphere. The ductile response of the lower lithosphere is represented by Maxwell-viscoelastic behaviour controlled by a temperature-activated diffusion process. Then, the decrease of viscosity with depth follows from the temperature profile, $T(z)$, according to Arrhenius' law:

$\eta(T)=\eta_{\infty} e^{\frac{A}{T}}$

where the influence of the pressure has been neglected. The parameter $A$ is the activation energy of the diffusion process divided by the general gas constant and $\eta_{\infty}:=\eta(\infty)$. In the following calculations, we will use $A=5.6 \times 10^{4} \mathrm{~K}$ and $\eta_{\infty} / \rho=$ $1.65 \times 10^{2} \mathrm{~m}^{2} \mathrm{~s}^{-1}$, which are average values of the mantle (Schubert et al, 1980).

The top of the viscoelastic lower lithosphere is taken at a depth of $42 \mathrm{~km}$. The temperature at this depth is assumed to be $873 \mathrm{~K}$ and increases downward with a gradient of $12 \mathrm{~K} \mathrm{~km}^{-1}$. This agrees with an intermediate temperature profile proposed for the Fennoscandian lithosphere (Pasquale et al., 1991). We furthermore assume that the thermally controlled lower lithosphere extends to a depth of $100 \mathrm{~km}$ corresponding to an isotherm of $1573 \mathrm{~K}$. Below this depth, the thermal transport mechanism changes from conduction to convection. Therefore, the temperature remains constant in the first approximation, and the viscosity is kept fixed at $10^{21} \mathrm{~Pa}$ s. For numerical convenience, the continuous viscosity variation in the lower lithosphere is approximated by three layers of constant viscosity, where the respective values are volume averages calculated from the viscosity profile (Vermeersen and Sabadini, 1997) and viscosities greater than $10^{25} \mathrm{~Pa}$ s are set to infinity (earth model V, Table 1). The following calculations apply to load model E and the three 
epochs considered.

\subsection{One glaciation}

We begin with the modifications of the isostatic stress field resulting from the viscoelasticity of the lithosphere for a single glaciation. Figure 6 shows that, at the LGM, the shear stresses have relaxed significantly in the basal lithosphere layer with a viscosity of $1.2 \times 10^{22} \mathrm{~Pa} s$, whereas, in the superjacent layer with a viscosity of $2.6 \times 10^{23} \mathrm{~Pa}$ s, the relaxation is much reduced. The layer with a viscosity of $5.7 \times 10^{24} \mathrm{~Pa} \mathrm{~s}$ is not distinguished from the elastic top layer by visible discontinuities in the isobars and therefore behaves effectively elastically for the single glaciation considered.

In accordance with this, the maximum shear-stress distribution in the upper lithosphere at the LGM is similar to that for earth model E (Fig. 2, top). A notable difference is that, for earth model $\mathrm{V}$ and below the load, the surface of vanishing maximum shear stress has moved upward by $\sim 10 \mathrm{~km}$. After the LGM, the relative differences between the shear stresses in the upper lithosphere increase and, for earth model $\mathrm{V}$, a seperate stress maximum associated with extension develops at the surface around the load axis.

In general, the stress field in the lower lithosphere of earth model $\mathrm{V}$ is quite complicated after the LGM. Compared to earth model E, higher shear stresses arise near $70 \mathrm{~km}$ depth and immediately above the base of the lithosphere at the PT. This can be explained by the fact that the viscoelastic lower lithosphere of earth model $\mathrm{V}$ responds effectively elastically during the relatively short time elapsed since the LGM. The changes in the shear stress between the LGM and the PT are therefore very similar for earth models $\mathrm{E}$ and $\mathrm{V}$, which results in a build-up of stresses in the lower lithosphere of earth model $\mathrm{V}$. 


\subsection{Ten glaciations}

Next, we discuss the modifications of the isostatic stress field in the viscoelastic lithosphere caused by assuming ten glaciations of the type specified above. Figure 7 shows that the stress relaxation has now penetrated also into the lithosphere layer with a viscosity of $5.7 \times 10^{24} \mathrm{~Pa}$ s. A comparison with Fig. 6 furthermore demonstrates that the stress relaxation in the layer with a viscosity of $2.6 \times 10^{23} \mathrm{~Pa}$ s has proceeded, whereas the stresses in the lowermost lithosphere layer are very similar after one and ten glaciations.

An inspection of the maximum shear-stress distribution and the stress regimes at the LGM in Fig. 6 and 7 reveals that the surface of vanishing shear stress has been shifted further upward by $\sim 5 \mathrm{~km}$ below the load after ten glaciations. The stress field in the effectively elastic part of the viscoelastic lithosphere therefore resembles that of an elastic lithosphere of less than $100 \mathrm{~km}$ in thickness.

After the LGM, the stress field for earth model $\mathrm{V}$ and ten glaciations differs markedly from that for earth model E (Fig. 2). Whereas the latter features maximum shear stresses not exceeding $\sim 2 \mathrm{MPa}$ near the surface and the base of the lithosphere at the PT, the former shows similar values near the surface, but may reach $\sim 4 \mathrm{MPa}$ near $60 \mathrm{~km}$ depth and immediately above the base of the lithosphere. The stress maxima at intermediate depths occur in a depth range characterized by nearly vanishing shear stresses for earth model E. Thus, they constitute a pronounced modification of the stress field caused by the finite viscosity of the lithosphere, although this modification may not be significant to the seismicity observed in Fennoscandia. The axial stress maximum at the PT associated with extension and indicated also for earth model $\mathrm{V}$ and one glaciation (Fig. 6) is even more pronounced for ten glaciations, and the stress values around the load axis are now comparable with those calculated for the two other maxima near the surface. 


\section{$5 \quad$ Concluding remarks}

In the preceeding sections, we have studied the response of simple Maxwell-viscoelastic earth models to axisymmetric load models. Simulating the Fennoscandian ice sheet by discs of fixed radius and time-dependent thickness, we have examined the sensitivity of the stress field to changes in load cross-section or lithosphere thickness and investigated its modifications caused by the presence of an asthenosphere or by the finite viscosity of the lithosphere. The main results are as follows.

(1) For earth model $\mathrm{E}$ with an elastic lithosphere, the isostatic stress field is in equilibrium at the LGM. After this, the stresses generally become smaller in magnitude, but the patterns of the maximum shear stresses and the stress regimes are largely preserved.

(2) The discontinuous change in thickness for load model $\mathrm{R}$ produces an oscillatory stress pattern with decreasing amplitude away from the margin. The sloping crosssections of load models $\mathrm{E}$ and $\mathrm{P}$ generate finite pressure gradients below the load, which results in modifications of the stress pattern in this region.

(3) An increase in lithosphere thickness results in a broadening of the stress maxima and their shifting away from the load margin. This is accompanied by an amplification of the magnitudes of the inner maxima and a reduction of those of the outer maxima.

(4) The presence of a low-viscosity asthenosphere in earth model A accelerates the stress relaxation in the lower lithosphere. In contrast to this are the intermediate depths in the lithosphere, where the stress magnitudes may temporarily increase. As a consequence, the regularity of the stress pattern is no longer preserved during the relaxation.

(5) The consideration of the finite lithosphere viscosity in earth model $\mathrm{V}$ mainly affects the layers of reduced viscosity above the base of the lithosphere, where shear stresses are attenuated at the LGM but may temporarily increase thereafter. In the upper lithosphere, the stress field at the LGM resembles that of an elastic lithosphere 
of reduced thickness. After the LGM, a further stress maximum associated with extension arises around the load axis.

(6) If the number of glaciations assumed increases from one to ten, the effects resulting from the finite viscosity of the lithosphere generally become more pronounced.

In brief, we have shown that reasonable changes of the parameters studied may produce rather complex modifications of the maximum shear-stress distribution and the stress regimes. In order to obtain reliable predictions of the glacially induced stress field in Fennoscandia, realistic estimates of the controlling parameters are therefore mandatory. Despite of these complications, the majority of the earth and load models investigated return surface shear stresses with maxima of $\sim 2 \mathrm{MPa}$ at the PT. Although this is smaller in magnitude than the values of 10-50 MPa proposed for the tectonic stresses, our results suggest the general importance of the isostatic stresses when discussing the origin of the seismicity observed in Fennoscandia.

\section{Appendix: Calculation of stress components}

Upon Laplace and Hankel transformations, the scalar forms in the $(r, z, t)$ domain of the incremental field equations, (1)-(4), can be recast into a first-order ordinary differential system in the $(k, z, s)$ domain:

$\frac{d}{d z} \widetilde{\mathbf{Y}}(k, z, s)=\mathbf{M}(k, s) \widetilde{\mathbf{Y}}(k, z, s)$,

where

$\widetilde{\mathbf{Y}}:=\left(\tilde{U}_{r}^{1}, \tilde{U}_{z}^{0}, \widetilde{\Sigma}_{r z}^{1}, \tilde{\Sigma}_{z z}^{0}\right)^{\top}$

and the elements of $\mathbf{M}$ involve the parameters of the layer considered. In (A2), upper case-symbols denote the Hankel transforms of the respective quantities with the superscript indicating the order of the Hankel transform, and the tilde denotes Laplace transformation. 
At the surface, the solution has to satisfy the incremental boundary conditions for frictionless loading:

$\tilde{\Sigma}_{r z}^{1}(k, 0, s)=0$

$\tilde{\Sigma}_{z z}^{0}(k, 0, s)=-\widetilde{L}^{0}(k, s)$,

where $\tilde{L}^{0}$ is the Laplace- and Hankel-transformed load pressure. Between layers, the incremental interface conditions require the continuity of the displacement and traction:

$\widetilde{\mathbf{Y}}(k, z-0, s)=\widetilde{\mathbf{Y}}(k, z+0, s)$,

where $z$ denotes the depth of the interface. In addition, the fields must remain regular for $z \rightarrow \infty$. The solution in the $(r, z, t)$ domain for $\mathbf{y}=\left(u_{r}, u_{z}, \sigma_{r z}, \sigma_{z z}\right)^{\top}$ follows upon inverse Hankel and Laplace transformations. All other incremental field components can be expressed as linear combinations of the components of this solution.

To calculate the incremental stress components $\sigma_{r r}$ and $\sigma_{\varphi \varphi}$, it is necessary to know the incremental pressure, $p$. According to the constitutive equation, (3), we have for the stress component $\sigma_{z z}$ the relation

$p=-\sigma_{z z}+2 \int_{0}^{t} \mu\left(t-t^{\prime}\right) \partial_{t^{\prime}} \partial_{z} u_{z}\left(t^{\prime}\right) d t^{\prime}$,

where, from the continuity equation, (2), it follows that

$\partial_{z} u_{z}=-\left(\partial_{r} u_{r}+\frac{1}{r} u_{r}\right)$.

Consideration of (A6) and (A7) in (3) gives

$$
\begin{aligned}
\sigma_{r r} & =\sigma_{z z}+2 \int_{0}^{t} \mu\left(t-t^{\prime}\right) \partial_{t^{\prime}}\left[2 \partial_{r} u_{r}\left(t^{\prime}\right)+\frac{1}{r} u_{r}\left(t^{\prime}\right)\right] d t^{\prime}, \\
\sigma_{\varphi \varphi} & =\sigma_{z z}+2 \int_{0}^{t} \mu\left(t-t^{\prime}\right) \partial_{t^{\prime}}\left[\partial_{r} u_{r}\left(t^{\prime}\right)+\frac{2}{r} u_{r}\left(t^{\prime}\right)\right] d t^{\prime} .
\end{aligned}
$$

The incremental stress components $\sigma_{r \varphi}$ and $\sigma_{z \varphi}$ are zero for the axisymmetric boundary conditions chosen. The principal stresses, $\sigma_{1}, \sigma_{2}$ and $\sigma_{3}$, are obtained by transforming the stress tensor to its principal axes in the usual way. 
Acknowledgements. The research of VK was supported by a graduate scholarship of the German Research Foundation (DFG). Constructive comments to the manuscript by Falk Amelung, Gottfried Grünthal and Patrick Wu are gratefully acknowledged. 


\section{References}

Arvidsson, R., 1996. Fennoscandian earthquakes: Whole crustal rupturing related to postglacial rebound. Science, 274: 744-746.

Breuer, D. and Wolf, D., 1995. Deglacial land emergence and lateral upper-mantle heterogeneity in the Svalbard Archipelago - I. First results for simple load models. Geophys. J. Int., 121: $775-788$.

Bungum, H., 1989. Earthquake occurence and seismotectonics in Norway and surrounding areas. In: Gregersen, S. and Basham, P. W. (Editors), Earthquakes at North-Atlantic Passive Margins: Neotectonics and Postglacial Rebound. Kluwer Academic Publishers, Dordrecht, pp. 501-520.

Comer, R. P., 1983. Thick plate flexure. Geophys. J. R. Astron. Soc., 72: 101-113.

Fjeldskaar, W., 1994. Viscosity and thickness of the asthenosphere detected from the Fennoscandian uplift. Earth Planet. Sci. Lett., 126: 399-410.

Gregersen, S., 1992. Crustal stress regime in Fennoscandia from focal mechanisms. J. Geophys. Res., Ser. B, 97: 11821-11827.

Grünthal, G. and Stromeyer, D., 1992. The recent crustal stress field in Central Europe: Trajectories and finite element modeling. J. Geophys. Res., Ser. B, 97: 11805-11820.

James, T. S. and Bent, A. L., 1994. A comparison of eastern North American seismic strain-rates to glacial rebound strain-rates. Geophys. Res. Lett., 21: 2127-2130.

Johnston, A. C., 1987. Suppression of earthquakes by large continental ice sheets. Nature, 330: $467-469$.

Johnston, A. C., 1989. The effect of large ice sheets on earthquake genesis. In: Gregersen, S. and Basham, P. W. (Editors), Earthquakes at North-Atlantic Passive Margins: Neotectonics and Postglacial Rebound. Kluwer Academic Publishers, Dordrecht, pp. 581-599.

Johnston, P., Wu, P., and Lambeck, K., 1998. Dependence of horizontal stress magnitude on load dimension in glacial rebound models. Geophys. J. Int., 132: in press. 
Kusznir, N. J., 1991. The distribution of stress with depth in the lithosphere; thermorheological and geodynamic constraints. Phil. Trans. R. Soc. London, Ser. A, 337: 95110.

Lagerbäck, R., 1979. Neotectonic structures in northern Sweden. Geol. Fören. Stockholm Förh., 100: 263-269.

Lundqvist, J., 1986. LateWeichselian glaciation and deglaciation in Scandinavia. Quat. Sci. Rev., 5: 269-292.

Mitrovica, J. X., 1996. Haskell [1935] revisited. J. Geophys. Res., Ser. B, 94: 555-569.

Muir Wood, R., 1989. Extraordinary deglaciation reverse faulting in northern Fennoscandia. In: Gregersen, S. and Basham, P. W. (Editors), Earthquakes at North-Atlantic Passive Margins: Neotectonics and Postglacial Rebound. Kluwer Academic Publishers, Dordrecht, pp. 141-173.

Müller, B., Zoback, M. 1., Fuchs, K., Mastin, L., Gregersen, S., Pavoni, N., Stephansson, O., and Ljunggren, C., 1992. Regional patterns of tectonic stress in Europe. J. Geophys. Res., Ser. B, 97: 11783-11803.

Pasquale, V., Verdoya, M., and Chiozzi, P., 1991. Lithospheric thermal structure in the Baltic shield. Geophys. J. Int., 106: 611-620.

Schubert, G., Stevenson, D., and Cassen, P., 1980. Whole planet cooling and the radiogenic heat source contents of the Earth and Moon. J. Geophys. Res., Ser. B, 85: 2531-2538.

Shackleton, N. J., Backman, J., Zimmerman, H., Kent, D. V., Hall, M. A., Roberts, D. G., Schnitker, D., Baldauf, J. G., Desprairies, A., Homrighausen, R., Huddlestun, P., Keene, J. B., Kaltenback, A. J., Krumsiek, K. A. O., Morton, A. C., Murray, J. W., and J., W.-S., 1984. Oxygen isotope calibration of the onset of ice-rafting and history of glaciation in the North Atlantic region. Nature, 307: 620-623.

Skordas, E. and Kulhánek, O., 1992. Spatial and temporal variations of Fennoscandian seismicity. Geophys. J. Int., 111: 577-588. 
Slunga, R. S., 1989. Focal mechanisms and crustal stresses in the Baltic Shield. In: Gregersen, S. and Basham, P. W. (Editors), Earthquakes at North-Atlantic Passive Margins: Neotectonics and Postglacial Rebound. Kluwer Academic Publishers, Dordrecht, pp. 261-267.

Sneddon, I. N., 1951. Fourier Transforms. McGraw-Hill, New York, NY.

Stein, S., Sleep, N., Geller, N., Wang, R., and Kroeger, G., 1979. Earthquakes along the passive margin of eastern Canada. Geophys. Res. Lett., 6: 537-540.

Stein, S., Cloething, S., Sleep, N. H., and Wortel, R., 1989. Passive margin earthquakes, stresses and rheology. In: Gregersen, S. and Basham, P. W. (Editors), Earthquakes at North-Atlantic Passive Margins: Neotectonics and Postglacial Rebound. Kluwer Academic Publishers, Dordrecht, pp. 231-259.

Vermeersen, L. L. A. and Sabadini, R., 1997. A new class of stratified viscoelastic models by analytical techniques. Geophys. J. Int., 129: 531-570.

Wahlström, R., 1989. Seismodynamics and postglacial faulting in the Baltic Shield. In: Gregersen, S. and Basham, P. W. (Editors), Earthquakes at North-Atlantic Passive Margins: Neotectonics and Postglacial Rebound. Kluwer Academic Publishers, Dordrecht, pp. $467-482$.

Wahlström, R., 1993. Fennoscandian seismicity and its relation to the isostatic rebound. Global Planet. Change, 8: 107-112.

Wolf, D., 1985a. Thick-plate flexure re-examined. Geophys. J. R. Astron. Soc., 80: 265273.

Wolf, D., 1985b. The normal modes of a layered, incompressible Maxwell half-space. J. Geophys., 57: 106-117.

Wolf, D., 1987. An upper bound on lithosphere thickness from glacio-isostatic adjustment in Fennoscandia. J. Geophys., 61: 141-149.

Wolf, D., 1991. Boussinesq's problem of viscoelasticity. Terra Nova, 3: 401-407. 
Wolf, D., 1993. The changing role of the lithosphere in models of glacial isostasy: A historical review. Global Planet. Change, 8: 95-106.

Wu, P., 1996. Changes in orientation of near-surface stress field as constraints to mantle viscosity and horizontal stress differences in eastern Canada. Geophys. Res. Lett., 23: $2263-2266$.

Wu, P., 1997. Effects of viscosity structure on fault potential and stress orientations in eastern Canada. Geophys. J. Int., 130: 365-382.

Wu, P. and Hasegawa, H. S., 1996a. Induced stresses and fault potential in eastern Canada due to a disc load: A preliminary analysis. Geophys. J. Int., 125: 415-430.

Wu, P. and Hasegawa, H. S., 1996b. Induced stresses and fault potential in eastern Canada due to a realistic load: A preliminary analysis. Geophys. J. Int., 127: 215-229. 


\section{Tables}

Table 1. Parameter values of the earth models considered. For earth model E, $h_{1}$ is a free parameter.

\begin{tabular}{l|rrrr} 
& $\rho\left[\mathrm{kg} \mathrm{m}^{-3}\right]$ & $\mu_{e}[\mathrm{GPa}]$ & $\eta[\mathrm{Pa} \mathrm{s}]$ & $h[\mathrm{~km}]$ \\
\hline Earth model E: & & & & \\
Lithosphere & 3380 & 64.0 & $\infty$ & $h_{1}$ \\
Upper mantle & 3380 & 145.0 & $1.0 \times 10^{21}$ & $\infty$ \\
& & & & \\
Earth model A: & & & & \\
Lithosphere & 3380 & 64.0 & $\infty$ & 100 \\
Asthenosphere & 3380 & 145.0 & $1.0 \times 10^{19}$ & 100 \\
Upper mantle & 3380 & 145.0 & $1.0 \times 10^{21}$ & $\infty$ \\
& & & & \\
Earth model V: & & & & \\
Upper lithosphere & 3380 & 64.0 & $\infty$ & 64 \\
Lower lithosphere & 3380 & 64.0 & $5.7 \times 10^{24}$ & 10 \\
& 3380 & 64.0 & $2.6 \times 10^{23}$ & 12 \\
& 3380 & 64.0 & $1.2 \times 10^{22}$ & 14 \\
Upper mantle & 3380 & 145.0 & $1.0 \times 10^{21}$ & $\infty$
\end{tabular}

Table 2. Parameter values and cross-sections of the load models considered.

\begin{tabular}{|c|c|c|c|c|c|}
\hline & $r_{L}[\mathrm{~km}]$ & $h_{L}[\mathrm{~m}]$ & Cross-section & & \\
\hline Load model $\mathrm{R}$ & 900 & 2800 & Rectangular & $\square h(r)=h_{L}, \quad r \leq r_{L}$ & \\
\hline Load model E & 900 & 2800 & Elliptic & $\square h(r)=h_{L} \sqrt{1-r^{2} / r_{L}^{2}}$ & $r \leq r_{L}$ \\
\hline Load model P & 900 & 2800 & Parabolic & $h(r)=h_{L}\left(1-r^{2} / r_{L}^{2}\right)$ & $r \leq r_{L}$ \\
\hline
\end{tabular}




\section{Figure Captions}

Fig. 1. Relaxation times as functions of the normalized wave number. The calculations apply to earth model $\mathrm{E}$ with $100 \mathrm{~km}$ lithosphere thickness. The symbols M0 and L0 denote relaxation modes. The normalized wave number is defined by $k R$ with $k$ the Hankel wave number and $R$ the Earth's radius.

Fig. 2. Isostatic stress field in the lithosphere for the epochs considered. The calculations apply to earth model $\mathrm{E}$ with $100 \mathrm{~km}$ lithosphere thickness and to load model E. The black bars indicate the radial range of the load. In (a), the maximum shear stress is shown with numbers on contours denoting the stress values in MPa. In (b), the stress regimes are shown with the extension regime indicated by dark grey, the thrust regime by light grey and the strike-slip regime by white.

Fig. 3. Isostatic stress field in the lithosphere for the load models considered. The calculations apply to earth model E with $100 \mathrm{~km}$ lithosphere thickness and to the LGM. For further explanations refer to Fig. 2.

Fig. 4. Isostatic stress field in the lithosphere for the lithosphere thicknesses considered. The calculations apply to earth model E, load model E and the LGM. For further explanations refer to Fig. 2.

Fig. 5. Isostatic stress field in the lithosphere for the epochs considered. The calculations apply to earth model A and load model E. For further explanations refer to Fig. 2.

Fig. 6. Isostatic stress field in the lithosphere for the epochs considered. The calculations apply to earth model V, load model $\mathrm{E}$ and one glaciation. For further explanations refer to Fig. 2. 
Fig. 7. Isostatic stress field in the lithosphere for the epochs considered. The calculations apply to earth model V, load model E and ten glaciations. For further explanations refer to Fig. 2. 


\section{Figures}

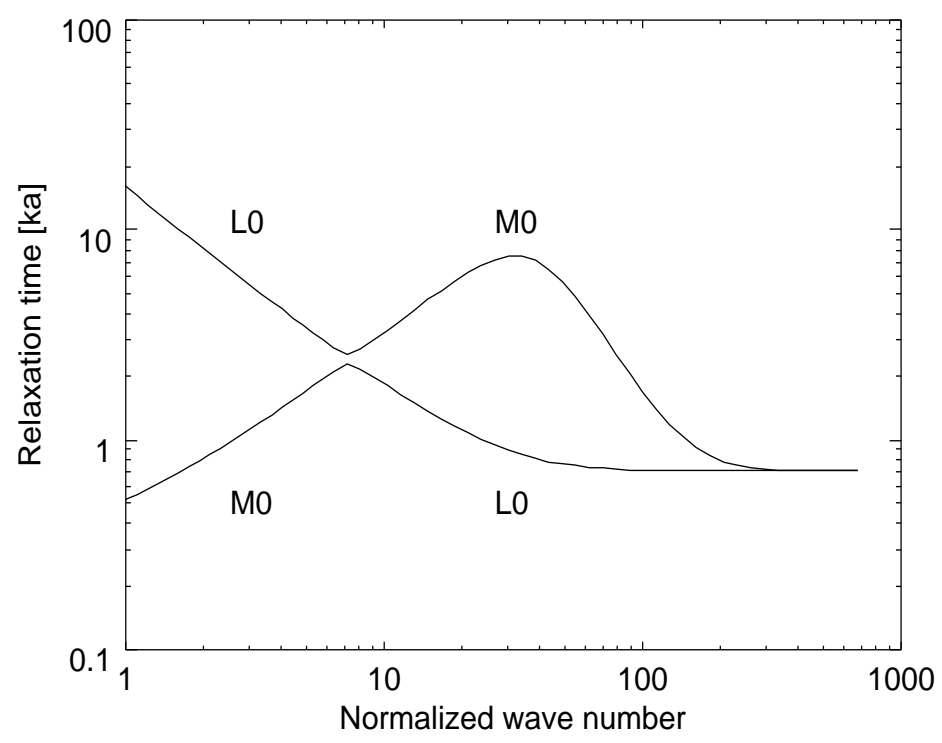

Fig. 1. Relaxation times as functions of the normalized wave number. The calculations apply to earth model $\mathrm{E}$ with $100 \mathrm{~km}$ lithosphere thickness. The symbols M0 and L0 denote relaxation modes. The normalized wave number is defined by $k R$ with $k$ the Hankel wave number and $R$ the Earth's radius. 
(a) Maximum shear stress

(b) Stress regimes

Last glacial maximum
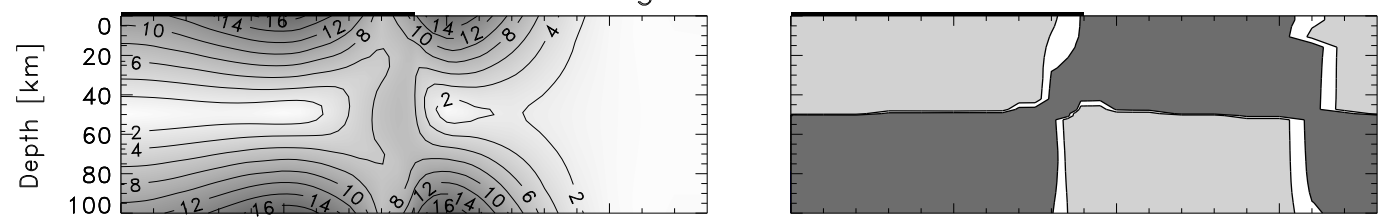

End of deglaciation
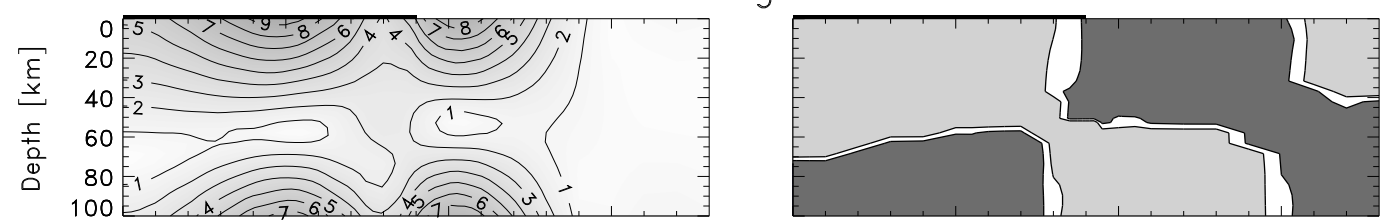

Present time
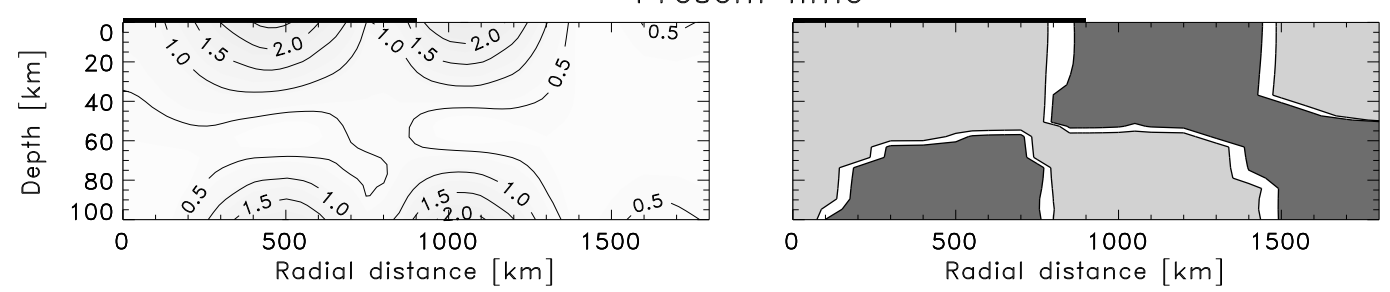

Fig. 2. Isostatic stress field in the lithosphere for the epochs considered. The calculations apply to earth model $\mathrm{E}$ with $100 \mathrm{~km}$ lithosphere thickness and to load model E. The black bars indicate the radial range of the load. In (a), the maximum shear stress is shown with numbers on contours denoting the stress values in MPa. In (b), the stress regimes are shown with the extension regime indicated by dark grey, the thrust regime by light grey and the strike-slip regime by white. 
(a) Maximum shear stress

(b) Stress regimes

Rectangular cross-section
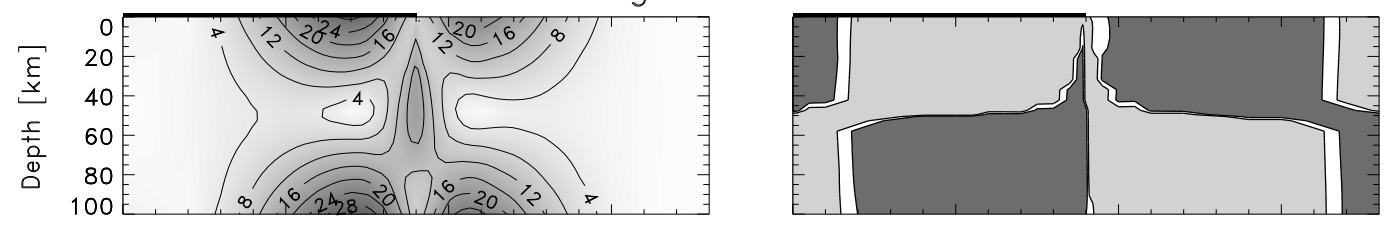

Elliptic cross-section
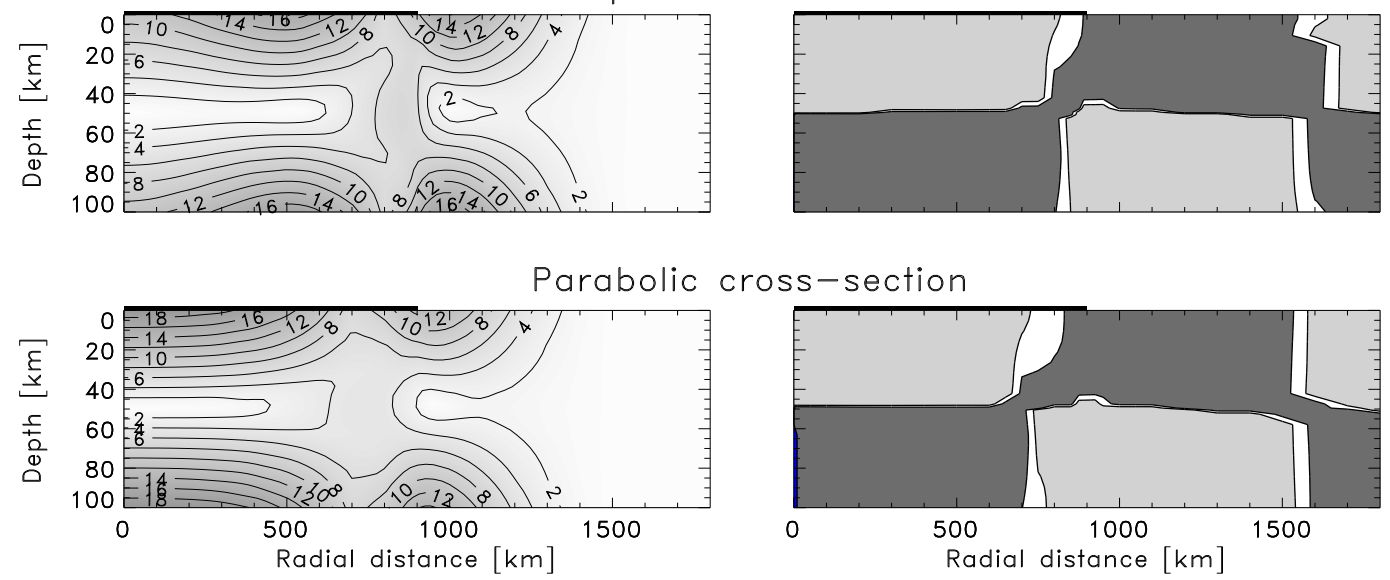

Fig. 3. Isostatic stress field in the lithosphere for the load models considered. The calculations apply to earth model $\mathrm{E}$ with $100 \mathrm{~km}$ lithosphere thickness and to the LGM. For further explanations refer to Fig. 2. 
(a) Maximum shear stress

Lithosphere thickness $50 \mathrm{~km}$
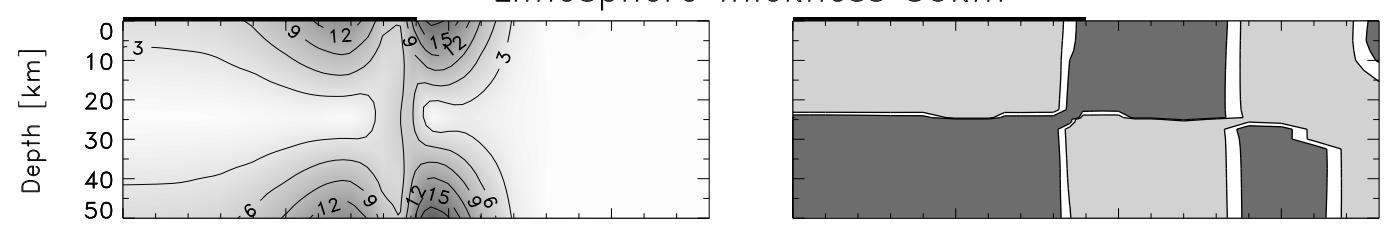

Lithosphere thickness $100 \mathrm{~km}$
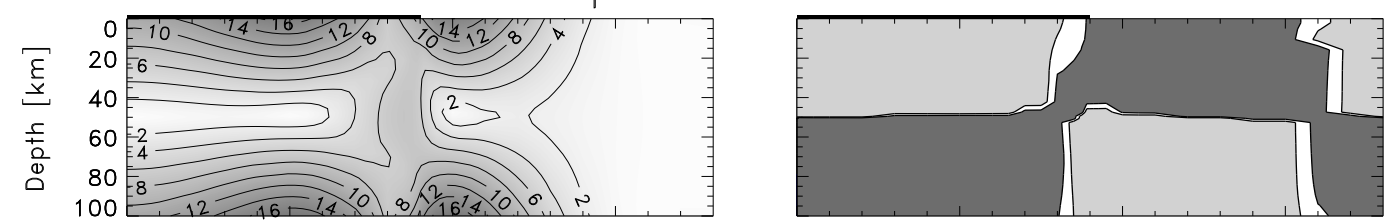

Lithosphere thickness $150 \mathrm{~km}$
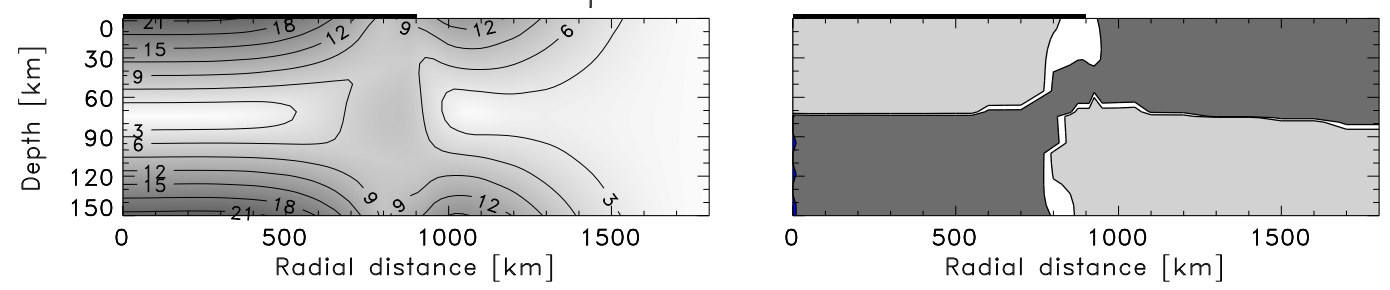

Fig. 4. Isostatic stress field in the lithosphere for the lithosphere thicknesses considered. The calculations apply to earth model E, load model E and the LGM. For further explanations refer to Fig. 2. 
(a) Maximum shear stress

(b) Stress regimes

Last glacial maximum
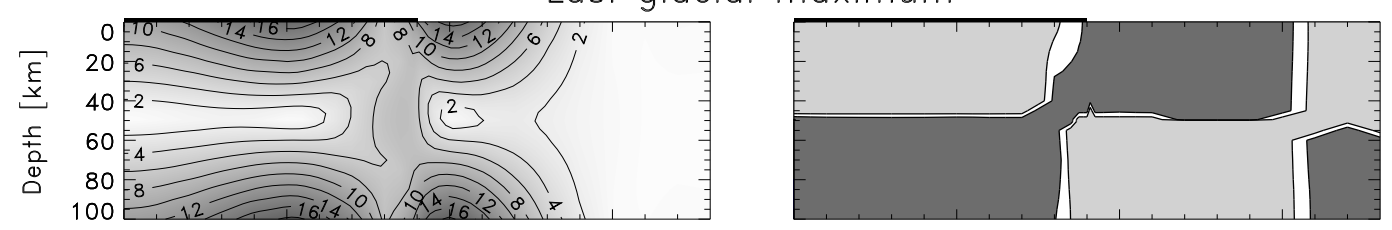

End of deglaciation
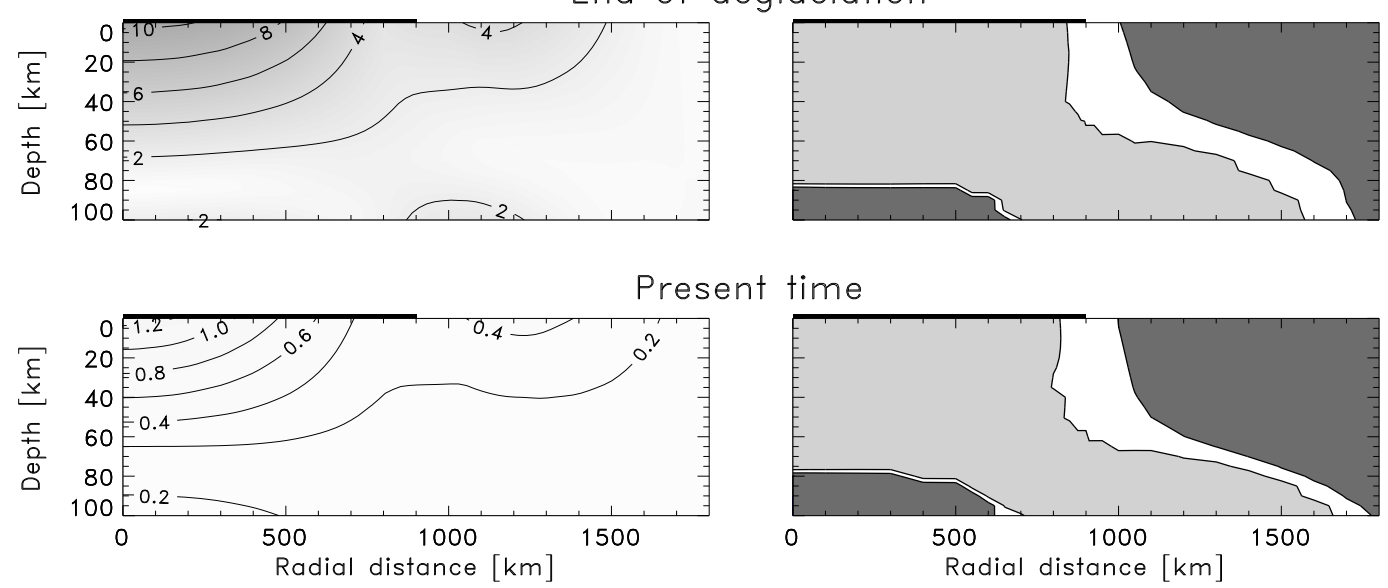

Fig. 5. Isostatic stress field in the lithosphere for the epochs considered. The calculations apply to earth model A and load model E. For further explanations refer to Fig. 2. 
(a) Maximum shear stress

(b) Stress regimes

Last glacial maximum
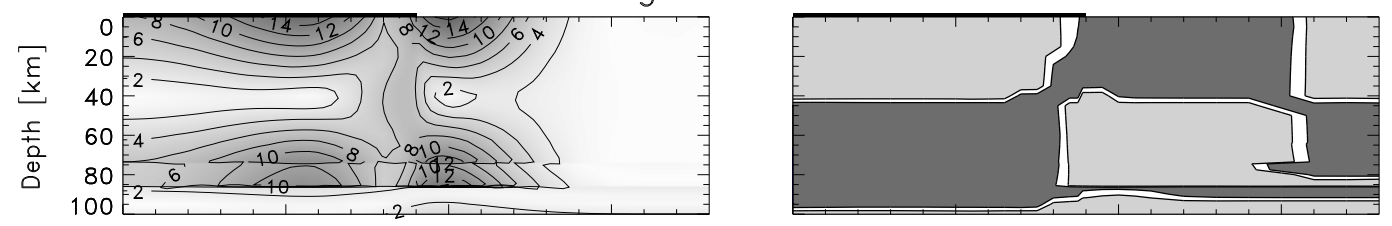

End of deglaciation
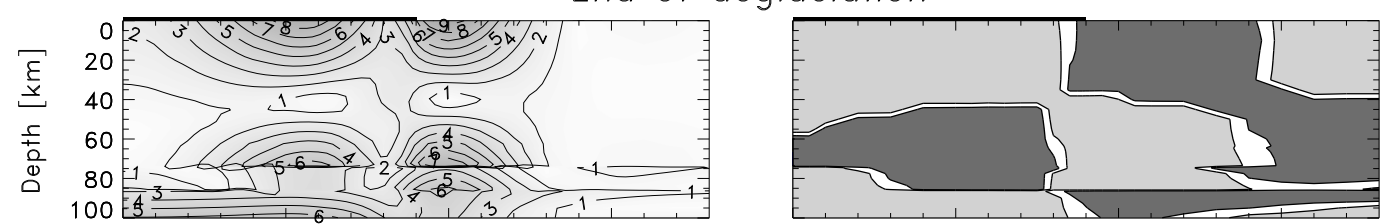

Present time
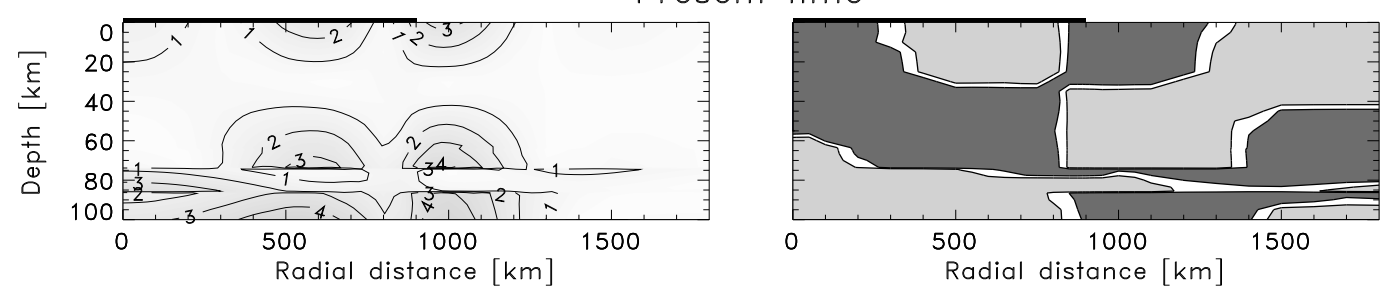

Fig. 6. Isostatic stress field in the lithosphere for the epochs considered. The calculations apply to earth model $\mathrm{V}$, load model $\mathrm{E}$ and one glaciation. For further explanations refer to Fig. 2. 
(a) Maximum shear stress

(b) Stress regimes

Last glacial maximum
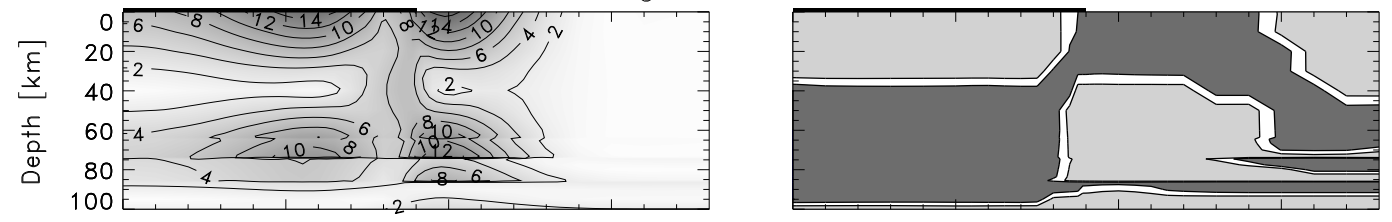

End of deglaciation
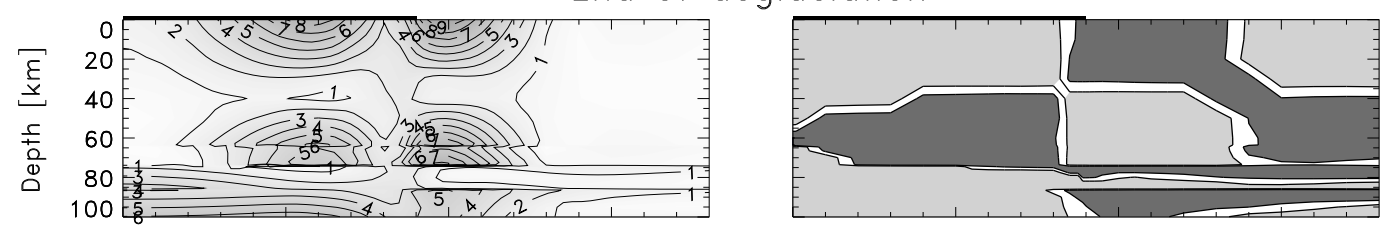

Present time
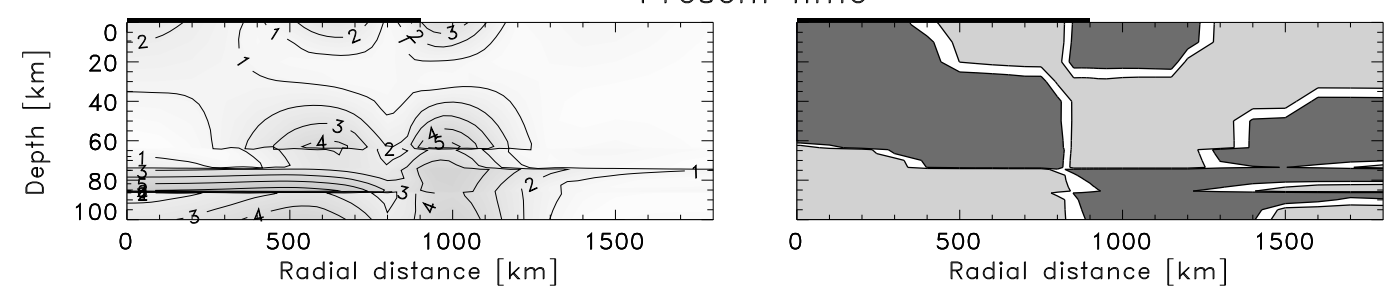

Fig. 7. Isostatic stress field in the lithosphere for the epochs considered. The calculations apply to earth model $\mathrm{V}$, load model $\mathrm{E}$ and ten glaciations. For further explanations refer to Fig. 2. 